\title{
Type 2 Diabetes Management, Control and Outcomes During the COVID-19 Pandemic in Older US Veterans: an Observational Study
}

\author{
Carole E. Aubert, MD, MSc $c^{7,2,3,4}{ }_{\mathbb{D}}$, James B. Henderson, PhD ${ }^{3,5}$, Eve A. Kerr, MD, MPH, ${ }^{3,4,6}$, \\ Rob Holleman, $\mathrm{MPH}^{3}$, Mandi L. Klamerus, $\mathrm{MPH}^{3}$, and Timothy P. Hofer, MD, MSC $\mathrm{C}^{3,4,6}$
}

\begin{abstract}
'Department of General Internal Medicine, Bern University Hospital, Inselspital, University of Bern, Freiburgstrasse, Bern, Switzerland; ${ }^{2}$ Institute of Primary Health Care (BIHAM), University of Bern, Bern, Switzerland; ${ }^{3}$ Center for Clinical Management Research, Veterans Affairs Ann Arbor Healthcare System, Ann Arbor, MI, USA; ${ }^{4}$ Institute for Healthcare Policy and Innovation, University of Michigan, Ann Arbor, MI, USA; ${ }^{5}$ Consulting for Statistics, Computing \& Analytics Research (CSCAR), University of Michigan, Ann Arbor, MI, USA; ${ }^{6}$ Department of Internal Medicine, University of Michigan, Ann Arbor, MI, USA.
\end{abstract}

BACKGROUND: The COVID-19 pandemic required a change in outpatient care delivery models, including shifting from in-person to virtual visits, which may have impacted care of vulnerable patients.

OBJECTIVE: To describe the changes in management, control, and outcomes in older people with type 2 diabetes (T2D) associated with the shift from in-person to virtual visits.

DESIGN AND PARTICIPANTS: In veterans aged $\geq 65$ years with T2D, we assessed the rates of visits (in person, virtual), Alc measurements, antidiabetic deintensification/intensification, ER visits and hospitalizations (for hypoglycemia, hyperglycemia, other causes), and Alc level, in March 2020 and April-November 2020 (pandemic period). We used negative binomial regression to assess change over time (reference: pre-pandemic period, July 2018 to February 2020), by baseline Charlson Comorbidity Index (CCI; > 2 vs. <= 2) and Alc level.

KEY RESULTS: Among 740,602 veterans (mean age 74.2 [SD 6.6] years), there were 55\% (95\% CI 52-58\%) fewer inperson visits, $821 \%$ (95\% CI 793-856\%) more virtual visits, 6\% (95\% CI 1-11\%) fewer Alc measurements, and 14\% (95\% CI 10-17\%) more treatment intensification during the pandemic, relative to baseline. Patients with CCI > 2 had a 14\% (95\% CI 12-16\%) smaller relative increase in virtual visits than those with $\mathrm{CCI}<=2$. We observed a seasonality of Alc level and treatment modification, but no association of either with the pandemic. After a decrease at the beginning of the pandemic, there was a rebound in other-cause (but not hypo- and hyperglycemia-related) ER visits and hospitalizations from June to November 2020.

CONCLUSION: Despite a shift to virtual visits and a decrease in Alc measurement during the pandemic, we observed no association with Alc level or short-term T2D-related outcomes, providing some reassurance about the adequacy of virtual visits. Further studies should assess the longer-term effects of shifting to virtual visits in different populations to help individualize care, improve efficiency, and maintain appropriate care while reducing overuse.

Received June 28, 2021

Accepted November 23, 2021

Published online January 6, 2022
KEY WORDS: type 2 diabetes; covid-19 pandemic; virtual care; elderly; veterans.

J Gen Intern Med 37(4):870-7

DOI: $10.1007 / \mathrm{s} 11606-021-07301-7$

(C) The Author(s) under exclusive licence to Society of General Internal Medicine 2021

\section{INTRODUCTION}

The pandemic caused by the novel coronavirus disease (COVID-19) threatened to overwhelm healthcare facilities in early hot spots and led to a widespread shift of priorities in healthcare. ${ }^{1}$ Healthcare resources were shifted away from chronic disease management and prevention, to support intensive care expansions. ${ }^{2-4}$ This is likely to have affected regular follow-up of patients with chronic conditions, such as diabetes, and concerns have been raised about indirect consequences of the COVID-19 pandemic on progression and complications of chronic conditions. ${ }^{5-7}$

Virtual (i.e., video and telephone) visits replaced most in-person visits during the initial phase of the pandemic. $^{4}$ While virtual visits may provide a quality of care similar to that of in-person visits for some disease states and specialties, it is not possible in a virtual visit to complete a full physical examination or laboratory testing, and thus, virtual visits are clearly not appropriate for all situations. Clinicians and patients may both have favored virtual visits for older adults with type 2 diabetes (T2D) in the pandemic, as they are at higher risk of infection and worse outcomes from COVID-19. ${ }^{8,9}$

People with T2D experienced changes in the frequency of visits and lab tests and visit modality in reaction to the pandemic. This offered the opportunity to study the association of these changes to T2D care processes and short-term outcomes. From July 2018 to November 2020, we computed the monthly rates of visits (in person, virtual, total), Alc measurements, A1c level, antidiabetic deintensification and intensification, and ER visits and hospitalizations. 


\section{METHODS}

\section{Study Population}

As part of a previous study examining appropriate use of medications and treatments, we had identified a national sample of active users of the Veterans Health Administration (VHA) between October 1, 2013, and September 30, 2015 , with follow-up data through end of $2020,{ }^{10}$ with the following inclusion criteria: $\geq 1$ visit at any clinic location (known as "stop codes") and $\geq 2$ visits with one of the following stop codes: primary care $(322,323,348,350$, $531)$ or specialty care $(303,305,306,309,310,312)$. For the current study, we selected from this cohort all veterans $\geq$ 65 years with T2D, still active users of the VHA between January 1, 2018, and December 31, 2019 (to allow for at least 2 months of follow-up before pandemic start), ${ }^{1,12}$ and with $\geq 1$ T2D-management visit during this period (definition below). T2D was defined as (1) two separate outpatient visits with an International Classification of Diseases Tenth Revision (ICD-10) T2D diagnosis code (ICD-10 E11) or (2) one acute inpatient visit with a T2D ICD-10 code, or any ambulatory fill of an antidiabetic between October 1, 2013, and December 31, 2019. To account for a natural reduction in the sample cohort with time, we assessed whether patients were still active users of the VHA during each month of the study period (July 1, 2019, to November 30, 2020), and described all numbers relative to the number of active users. This study was approved by the Ann Arbor VA Healthcare System IRB. Support for VA/CMS data provided by the Department of Veterans Affairs, VA Health Services Research and Development Service, VA Information Resource Center (Project Numbers SDR 02-237 and 98-004).

\section{Measures}

We developed an algorithm using VA stop codes and Evaluation and Management (E/M) Current Procedural Terminology codes to identify the type of care and method of care delivery (Supplemental Text 1, Fig. 1). First, we selected visits containing an outpatient E/M code to identify provider visits where decision-making related to evaluation and management occurs. Second, we used VA stop codes to identify primary care, geriatrics, and endocrinology visits. Third, we used stop codes to identify visits to providers most likely to manage T2D (physician, nurse practitioner, physician assistant). Fourth, we identified stop codes specific to virtual visits. Fifth, we identified $\mathrm{E} / \mathrm{M}$ codes specific to virtual visits (because a few visits were coded with 2 stop codes not mentioning virtual visits, but these E/M codes are specific to virtual visits). Sixth, we excluded E/M codes specific to virtual visits paired to the VA stop code "319 MHV Secure Messaging," since this does not usually involve decision-making or real-time communication. Finally, we classified those visits as in person or virtual. Virtual visits included telephone and video visits, but not messaging. We defined baseline visit for each patient as the first visit between January 1, 2018, and December 31, 2019. We aggregated visits into monthly counts for in-person, virtual, and total visits, respectively.

We computed the Charlson Comorbidity Index (CCI) using ICD codes and classified patients into two groups of morbidity severity ( $\leq 2$ vs. $>2$ ), based on predicted mortality rates in the original publication. ${ }^{13}$ We defined four A1c categories to evaluate T2D control, based on VA guidelines for T2D management and our previous analysis on T2D overtreatment ${ }^{14,15}$ : $<6.0 \%, 6.0-6.9 \%, 7.0-8.4 \%$, and $\geq 8.5 \%$. Baseline A1c was defined as the closest measurement within 6 months of the baseline visit.

We used VA pharmacy fills to assess antidiabetic change each month. As previously, ${ }^{14}$ we defined deintensification as decreasing the number or dose of previously prescribed antidiabetics (no refill of an antidiabetic, or refill at a lower dose, within 180 days of the first of each month). We defined intensification as a fill for a new antidiabetic, or a refill at a higher dose. Deintensification was compared to no deintensification, for patients being treated with $\geq 1$ antidiabetic other than metformin. Intensification was compared to no intensification for all patients.

We classified ER visits and hospitalizations as related to hypoglycemia (ICD-10 codes: E11.64, E11.641, E11.649) or hyperglycemia (ICD-10 codes: E11.65, E11.0, D11.00, E11.01, E11.1, E11.10, E11.11).

\section{Time Periods}

To assess the impact of the pandemic, we compared the measures in March 2020 (pandemic declaration month), and April-November 2020 (pandemic period), to a pre-pandemic period (July 2018 to February 2020). The pre-pandemic period started 6 months after the inclusion start date, to allow for a look-back period for A1c measurements.

\section{Statistical Analyses}

For each calendar month, aggregating all patients, we assessed the visit (in person, virtual, total visits), A1c measurement, deintensification, intensification, ER visit and hospitalization rates, and the proportions of in-person/virtual visits and of patients in each A1c category. Each rate was the number per 1000 patients active at the VHA during that month. To assess differences according to T2D control and comorbidity severity, we conducted stratified analyses by baseline CCI ( $<=2$ vs. $>2$ ) and A1c category. A1c categories were used as a timevarying covariate: for each month, we determined the A1c category for each patient using the most recent A1c measurement within 6 months.

We used negative binomial regression to compare monthly rates and proportions during the pandemic declaration month 


\section{$\mathrm{E} / \mathrm{M}$ code for visits where decision-making is done by qualified HCP (1)}

\section{Visits with HCP making decision for diabetes management: primary care, geriatrics, endocrinology: \\ - Stop code from 2) without other stop code \\ - 2 stop codes from 2) \\ - Stop code from 2) paired with stop code from 3)}

\begin{tabular}{|l|l|}
\hline In-person visit: & Virtual visit: \\
- No stop code from 4) & $-\quad$ Stop code from 4) \\
and & No E/M code from 5) \\
& $-\quad$ E/M code from 5) \\
& $-\quad$ Not: E/M from 5) \\
& with stop code 719 \\
\hline
\end{tabular}

Figure 1 Algorithm for visit identification. Legend: We used both E/M and VA "stop codes" (clinic location) to identify visits to include in our analysis, as detailed in Supplemental Text 1. 1) E/M codes for visits with decision-making by a qualified healthcare provider; 2) stop codes for primary care, geriatrics, and endocrinology visits; 3) stop codes for visits by physician, nurse practitioner or physician assistant; 4) stop codes specific to virtual visits; 5) E/M codes specific to virtual visits.

and the pandemic period, compared to baseline. We used a piecewise linear time basis (e.g., an interaction between categorical and linear time) to model time trends relative to the pandemic (exposure: monthly number of active patients) with robust variance to account for autocorrelation. To account for seasonality in the distribution among A1c categories, A1c measurement rates, deintensification, intensification, ER visits, and hospitalizations, we included variables representing a basis expansion of the calendar month ( $\mathrm{K}$ variables forming a periodic cubic regression spline basis of dimension $4+2$ and period 12, with the dimension chosen to minimize Akaike information criterion (AIC)). ${ }^{16}$ We adjusted all analyses for CCI, A1c category, and region (North, South, East, West). We assessed for interactions between time variables themselves, and $\mathrm{CCI}$ and A1c categories in the stratified analyses, and retained the model with the lower AIC for each outcome. We presented results as incidence rate ratios (IRRs) with 95\% confidence intervals (CI). For the stratified analyses, we presented the relative risk ratios and the difference in the absolute difference in rates, comparing $\mathrm{CCI}>2$ to $\leq 2$, and each A1c category to $7.0-8.4 \%$ category. For ER visits and hospitalizations, we introduced an additional variable for the reason for care (hypoglycemia, hyperglycemia, other cause), and presented the results as relative risk ratios for hypoglycemia or hyperglycemia versus other causes. We performed all analyses with Stata/MP 15.1 (StataCorp).
RESULTS

\section{Study Population}

Among 740,602 veterans, mean age was 74.2 years at baseline (Table 1). Baseline A1c was $6.0-8.4 \%$ in $72 \%$ of patients. Patients with CCI $>2(N=281,576,38 \%)$ were slightly older than those with $\mathrm{CCI}<=2$ (mean age 74.8 vs. 73.8 years, $p<$ 0.001 ).

\section{Composition and Volume of Visits}

There were 55\% (95\% CI 52-58\%) fewer in-person and $824 \%$ (95\% CI 793-856\%) more virtual visits, with a net result of $10 \%(95 \%$ CI $7-13 \%)$ more total visits in April-November 2020 compared to the pre-pandemic period (Table 2). Pre pandemic, $90 \%$ of visits were in person and $10 \%$ virtual (Supplemental Figure 1). The proportion of in-person visits dropped in March 2020 and reached a nadir of $7 \%$ in April 2020. In-person visits started to increase again but did not reach prepandemic proportions before declining again from October to November 2020, coinciding with the COVID-19 second surge (Fig. 2). Patients with CCI $>2$ had a $14 \%$ (95\% CI $12-16 \%)$ smaller relative increase in virtual visits, while the reduction in in-person visits was not different. The relative change in visit rates did not differ according to the A1c level, but patients without a recent 
Table 1 Baseline Characteristics $(N=\mathbf{7 4 0 , 6 0 2})$

\begin{tabular}{|c|c|c|}
\hline Characteristic & $\begin{array}{l}\text { T2D without } \\
\text { complication }(N= \\
437,826)\end{array}$ & $\begin{array}{l}\text { T2D with } \\
\text { complication }(N= \\
\text { 302,776) }\end{array}$ \\
\hline Age, years & $74.3(6.6)$ & $74.0(6.5)$ \\
\hline Male & $429,937(98.2)$ & $298,557(98.6)$ \\
\hline $\begin{array}{l}\text { Systolic blood pressure, } \\
\mathrm{mmHg}\end{array}$ & $134.2(15.8)$ & $134.5(15.8)$ \\
\hline $\begin{array}{l}\text { Diastolic blood pressure, } \\
\mathrm{mmHg}\end{array}$ & $73.5(8.9)$ & $72.3(8.6)$ \\
\hline $\begin{array}{l}\text { Resting heart rate, beats } \\
\text { per min }\end{array}$ & $73.4(12.1)$ & $73.7(11.8)$ \\
\hline $\begin{array}{l}\text { Charlson Comorbidity } \\
\text { Index } \\
\text { Alc }\end{array}$ & $1.8(1.3)$ & $3.5(1.7)$ \\
\hline$<6.0 \%$ & $45,235(13,8)$ & $23,394(97)$ \\
\hline $6.0-6.9 \%$ & $130,429(39.8)$ & $73,992(30.7)$ \\
\hline $7.0-8.4 \%$ & $109,643(33.5)$ & 96,077 (39.9) \\
\hline$\geq 8.5 \%$ & $42,156(12.9)$ & $47,420(19.7)$ \\
\hline \multicolumn{3}{|l|}{ Chronic conditions } \\
\hline $\begin{array}{l}\text { Chronic kidney } \\
\text { disease }\end{array}$ & $48,262(11.0)$ & $87,872(29.0)$ \\
\hline $\begin{array}{l}\text { Congestive heart } \\
\text { failure }\end{array}$ & $35,876(8.2)$ & 48,699 (16.1) \\
\hline $\begin{array}{l}\text { Peripheral vascular } \\
\text { disease }\end{array}$ & $32,816(7.5)$ & 47,278 (15.6) \\
\hline $\begin{array}{c}\text { Cancer with/ } \\
\text { without metastasis }\end{array}$ & $44,880(10.3)$ & $34,970(11.5)$ \\
\hline $\begin{array}{l}\text { Cerebrovascular } \\
\text { disease }\end{array}$ & $31,216(7.1)$ & $34,683(11.5)$ \\
\hline Dementia & $15,180(3.5)$ & $13,965(4.6)$ \\
\hline \multicolumn{3}{|l|}{ Antidiabetic medication } \\
\hline Metformin & $150,039(34.3)$ & $106,352(35.1)$ \\
\hline Insulin & $68,206(15.6)$ & $100,555(33.2)$ \\
\hline Sulfonylurea & $77,988(17.8)$ & $62,530(20.7)$ \\
\hline DPP-4 inhibitor & $15,688(3.6)$ & $15,028(5.0)$ \\
\hline GLP-1 & $2701(0.6)$ & $5176(1.7)$ \\
\hline SGLT2 inhibitor & $2042(0.5)$ & $2907(1.0)$ \\
\hline & $2018(0.5)$ & $2124(0.70)$ \\
\hline \multicolumn{3}{|l|}{$\begin{array}{l}\text { Visits during the study } \\
\text { period }^{\dagger}\end{array}$} \\
\hline Virtual & $1.4(1.9)$ & $1.6(2.4)$ \\
\hline In person & $3.7(2.6)$ & $4.5(3.4)$ \\
\hline \multicolumn{3}{|l|}{ Region } \\
\hline North central & $104,168(23.8)$ & $75,696(25.0)$ \\
\hline Northeast & $61,074(14.0)$ & $41,108(13.6)$ \\
\hline South & 194,419 (44.4) & $135,271(44.7)$ \\
\hline West & $78,165(17.9)$ & $50,701(16.8)$ \\
\hline
\end{tabular}

Data are $N(\%)$ or mean (standard deviation)

Alc hemoglobin Alc, DPP dipeptidyl peptidase, GLPglucagon-like peptide, SGLTsodium-glucose-linked transporter

568,346 (77\%) had an Alc measurement within 6 months of baseline visit

July 2018 to November 2020

A1c measurement showed different trajectories (e.g., larger drop in in-person and total visits; Fig. 2, Supplemental Tables 1 and 2).

\section{Alc Measurements}

A1c measurement rates were $31 \%$ (95\% CI 28-34\%) lower in March 2020 and $96 \%$ (95\% CI 1-11\%) lower on average in April-November 2020 (Table 2, Fig. 3). The nadir was in April 2020. There was no difference in the change in A1c measurement rates according to the $\mathrm{CCI}$ or Alc level. We observed a second drop in measurements from October to November 2020, corresponding to the second surge.
Table 2 Incidence Rate Ratio and Relative Risk Ratio According to Pandemic Time and Charlson Comorbidity Index, for Visits, A1c Measurement, Deintensification, and Intensification

\begin{tabular}{llll}
\hline \hline & Incidence & Relative & Difference \\
rate ratio & risk ratio & in difference \\
$(95 \%$ CI), & $(95 \%$ CI) & in absolute \\
relative to & for CCI $>2$ & rates for \\
baseline & vs. $\leq 2$ & CCI $>2$ vs. \\
period & & $\leq 2$ \\
\hline
\end{tabular}

Follow-up rate

In-person visit

\begin{tabular}{|c|c|c|c|}
\hline & & & \\
\hline March 2020 & $\begin{array}{l}0.61(0.59 \\
\text { to } 0.62)\end{array}$ & $\begin{array}{l}0.95(0.93 \\
\text { to } 0.98)\end{array}$ & $\begin{array}{l}-16.7(- \\
19.5 \text { to }- \\
13.0)\end{array}$ \\
\hline $\begin{array}{r}\text { April- } \\
\text { November } 2020\end{array}$ & $\begin{array}{l}0.45(0.42 \\
\text { to } 0.48)\end{array}$ & $\begin{array}{l}0.98(0.94 \\
\text { to } 1.02)\end{array}$ & $\begin{array}{l}-21.1(- \\
24.2 \text { to }- \\
18.0)\end{array}$ \\
\hline \multicolumn{4}{|l|}{ Virtual visit rate } \\
\hline March 2020 & $\begin{array}{l}4.50(4.29 \\
\text { to } 4.72)\end{array}$ & $\begin{array}{l}0.89(0.85 \\
\text { to } 0.92)\end{array}$ & $\begin{array}{l}8.1(4.9 \text { to } \\
11.3)\end{array}$ \\
\hline $\begin{array}{c}\text { April- } \\
\text { November } 2020 \\
\text { Total visit rate }\end{array}$ & $\begin{array}{l}8.24(7.93 \\
\text { to } 8.56)\end{array}$ & $\begin{array}{l}0.86(0.84 \\
\text { to } 0.88)\end{array}$ & $\begin{array}{l}17.7(14.5 \text { to } \\
20.9)\end{array}$ \\
\hline March 2020 & $\begin{array}{l}0.93(0.91 \\
\text { to } 0.95)\end{array}$ & $\begin{array}{l}0.97(0.95 \\
\text { to } 0.99)\end{array}$ & $\begin{array}{l}-7.8(-11.8 \\
\text { to }-3.7)\end{array}$ \\
\hline $\begin{array}{r}\text { April- } \\
\text { November } 2020\end{array}$ & $\begin{array}{l}1.10(1.07 \\
\text { to } 1.13)\end{array}$ & $\begin{array}{l}0.96(0.95 \\
\text { to } 0.98)\end{array}$ & $\begin{array}{l}-3.5(-7.2 \\
\text { to } 3.1)\end{array}$ \\
\hline A1c measurement & & & \\
\hline March 2020 & $\begin{array}{l}0.69(0.66 \\
\text { to } 0.72)\end{array}$ & $\begin{array}{l}\text { No } \\
\text { interaction }\end{array}$ & $\begin{array}{l}\text { No } \\
\text { interaction }\end{array}$ \\
\hline $\begin{array}{c}\text { April- } \\
\text { November } 2020\end{array}$ & $\begin{array}{l}0.94(0.89 \\
\text { to } 0.99)\end{array}$ & $\begin{array}{l}\text { between } \\
\text { time and } \\
\text { CCI }\end{array}$ & $\begin{array}{l}\text { between time } \\
\text { and CCI }\end{array}$ \\
\hline \multicolumn{4}{|l|}{$\begin{array}{l}\text { Medication } \\
\text { Deintensification } \\
\text { rate }\end{array}$} \\
\hline March 2020 & $\begin{array}{l}0.91(0.89 \\
\text { to } 0.93)\end{array}$ & $\begin{array}{l}1.00(0.98 \\
\text { to } 1.02)\end{array}$ & $\begin{array}{l}-2.6(-6.0 \\
\text { to } 0.9)\end{array}$ \\
\hline $\begin{array}{l}\qquad \text { April- } \\
\text { September 2020 } \\
\text { Intensification rate }\end{array}$ & $\begin{array}{l}1.03(1.01 \\
\text { to } 1.05)\end{array}$ & $\begin{array}{l}0.98(0.97 \\
\text { to } 1.00)\end{array}$ & $\begin{array}{l}-2.2(-4.8 \\
\text { to } 0.4)\end{array}$ \\
\hline $\begin{array}{l}\text { nsification rate } \\
\text { March } 2020\end{array}$ & $\begin{array}{l}1.09(1.05 \\
\text { to } 1.12)\end{array}$ & $\begin{array}{l}0.97(0.95 \\
\text { to } 0.99)\end{array}$ & $\begin{array}{l}-1.8(-4.2 \\
\text { to } 0.5)\end{array}$ \\
\hline $2020^{\text {April-September }}$ & $\begin{array}{l}1.14(1.10 \\
\text { to } 1.17)\end{array}$ & $\begin{array}{l}0.97(0.96 \\
\text { to } 0.99)\end{array}$ & $\begin{array}{l}-1.8(-3.7 \\
\text { to } 0.09)\end{array}$ \\
\hline
\end{tabular}

The reference period (baseline, or pre-pandemic period) was defined as July 2018 to February 2020 for visit and Alc measurement rates, and July 2018 to May 2020 for deintensification and intensification rates (to account for the 90-day usual refill period used to calculate treatment modification). Medication data were available until September only. All models were adjusted for CCI, time-varying Alc category, and time periods. To account for seasonality in the distribution among Alc measurements and treatment modification, we included in addition variables representing a basis expansion of the calendar month. A relative risk ratio $>1.00$ means that the incidence rate ratio was higher for patients with $C C I>2$, while a relative risk ratio $<1.00$ means that the incidence rate ratio was higher for patients with $C C I \leq 2$ point(s). Difference-in-differences(DID) estimates $<0.0$ indicate a larger absolute change in the visit rate for patients with $C C I \leqq 2$, while a positive DID $(>0.0)$ indicates a larger absolute change for patients with $C C I>2$

Alc hemoglobin Alc, CCI Charlson Comorbidity Index, CI confidence interval

\section{Diabetes Control and Treatment Modification}

We detected a seasonal effect of A1c levels: peak in January, nadir in October, but no association with the pandemic (Supplemental Figure 2). We observed a corresponding seasonal effect in treatment modification: 

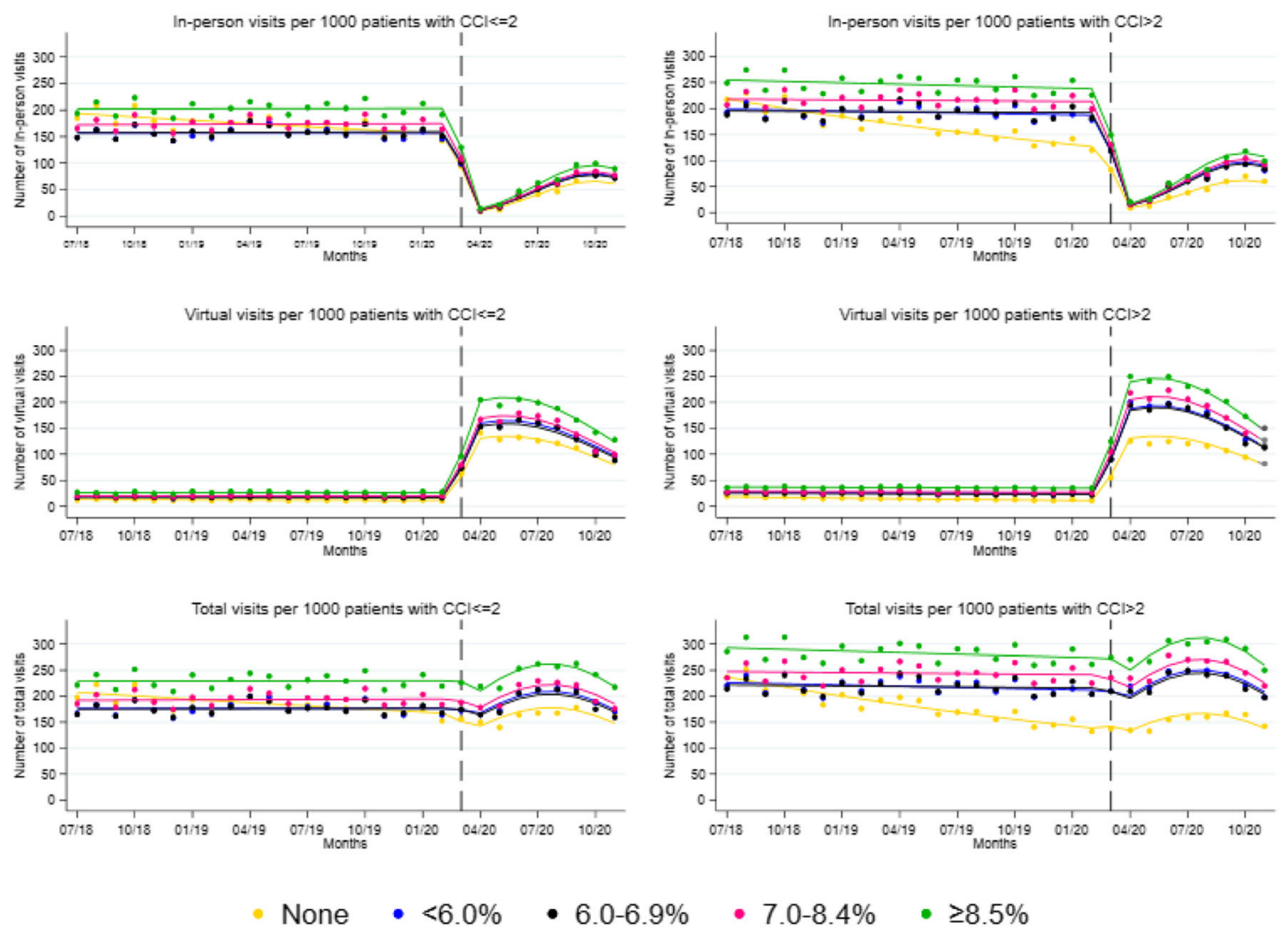

Figure 2 Visit rates according to time, Charlson Comorbidity Index, and A1c level. Abbreviations: A1c, hemoglobin A1c; CCI, Charlson Comorbidity Index. Legend: The dots display the observed rates, and the lines the predicted rates. The dashed line shows the month of March 2020 (pandemic declaration month).

more intensification in winter, more deintensification in summer (Fig. 4, Supplemental Figures 3 and 4). Compared to baseline, deintensification rates were not different during the pandemic, while intensification rates increased by $14 \%$ (95\% CI $10-17 \%$; Table 2$)$. The relative increase was slightly smaller in patients with $\mathrm{CCI} \geq$ 2 , compared to those with $\mathrm{CCI}<2$, and in those without A1c measurement, compared to those with A1c 7.0-8.4\% (Table 2, Supplemental Tables 1 and 2). There was a relative increase in deintensification during the pandemic in patients without A1c measurement, compared to those with A1c 7.0-8.4\%.

\section{ER Visits and Hospitalizations}

Following a drop in other-cause (but not hypoglycemia- and hyperglycemia-related) ER visits and hospitalizations in March-May 2020, we observed a rebound in JuneNovember 2020 (Supplemental Table 3, Supplemental Figure 5).

\section{DISCUSSION}

In over 740,000 older veterans with $\mathrm{T} 2 \mathrm{D}$, we found a dramatic increase in virtual visits involving clinical decision-making for
T2D care during the pandemic, overcompensating for the drop in in-person visits. Before the pandemic, $90 \%$ of visits were in person, while in April 2020, over 90\% of visits took place virtually. There was an expected parallel drop in A1c measurement rates and a slight increase in intensification rates. These modifications in management and care did not affect T2D control or hypoglycemia- or hyperglycemia-related ER visits and hospitalizations.

The decrease in in-person visits and increase in virtual visits were expected and comparable to what was observed in other healthcare systems in the USA, ${ }^{17-21}$ although large differences according to specialties have been described. ${ }^{20}$ However, the increased total visits in the first wave of the pandemic were less expected and have not been described, but previous analyses were often limited to the early months of the pandemic or used a commercially insured population with different reimbursement conditions than in the VHA. ${ }^{17-21}$ In November 2020 (second surge), we observed a second drop in inperson visits and A1c measurements, but smaller than the first, and not overcompensated by virtual visits, suggesting more familiarity with virtual visits, along with better understanding of COVID-19 risks and access to adequate protection.

It is unclear why there would be more total visits in the first surge of COVID-19, and unfortunately, the VA scheduling package contains little or no information about the reasons for 


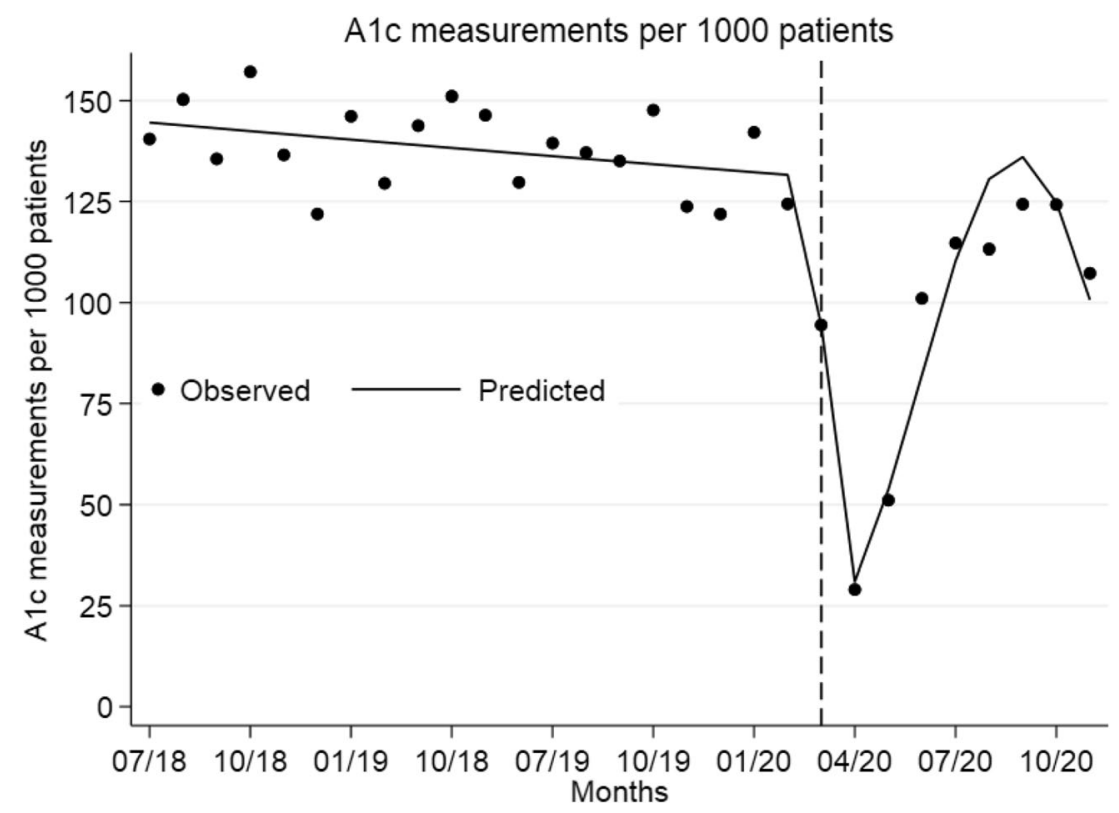

Figure 3 A1c measurement rates according to time. Abbreviations: A1c, hemoglobin A1c. Legend: The dashed line shows the month of March 2020 (pandemic declaration month).

visits. There are several potential explanations which may individually or collectively have led to this increase in visits, which at this point are only speculative. First, a lack of familiarity with virtual visits may have led the providers to feel a need for more frequent follow-ups. Second, there was concern about a mental health crisis among older adults, given the disruptions in access to care and greater social isolation and loneliness (often compounded by challenges in using digital technologies). Third, patients with T2D are at higher risk not only of complications and worse outcomes of COVID-19, ${ }^{8,9}$ but also of depression. ${ }^{22-24}$ Unable to provide usual care, clinicians may have increased the number of visits for their high-risk patients to provide the best care possible. Fourth, the availability of telephone care as an accepted virtual modality for follow-up may have decreased barriers to followup. Finally, patients potentially psychologically or physiologically impacted by the pandemic might have required and requested more care.

Patients with more comorbidities had a smaller relative increase in virtual visit rates with little difference in inperson visit rates. However, in comparison to their baseline virtual visit rates, patients with more comorbidities had a larger increase in virtual visit rates and larger decreases in inperson visit rates. Those patients may have worse access to, or less readiness to use, telehealth: $38 \%$ of older American adults would not be ready to use video visits, mostly because of inexperience with technology. ${ }^{25}$ This proportion increases with age, from $25 \%$ among the 65-74-year-old age group to $72 \%$ in the $\geq 85$-year-old age group. ${ }^{25}$ Patients with higher CCI were older, which may have further contributed to reduced access to, or willingness to use, virtual visits. Increased concern for exposure to COVID-19 may well have contributed
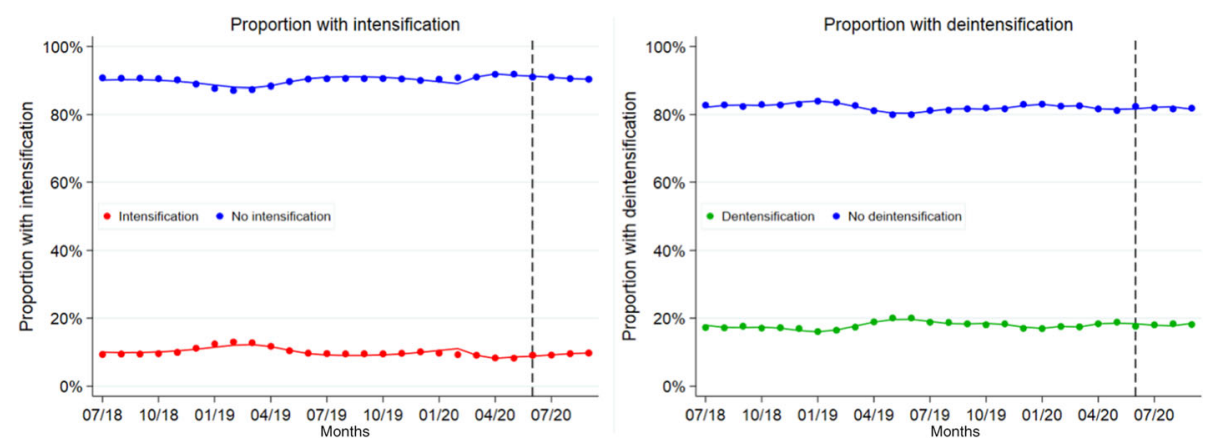

Figure 4 Proportions with intensification and with deintensification of antidiabetics, according to time. Legend: Deintensification was defined as a decrease in the number or dose of previously prescribed antidiabetics (no refill of an antidiabetic, or refill at a lower dose, within 180 days of the first of each month). Intensification was defined as a fill for a new antidiabetic or a refill at a higher dose. Deintensification was compared to no deintensification, for patients being treated with $\geq 1$ antidiabetic other than metformin. Intensification was compared to no intensification for all patients. The dots display the observed rates, and the lines the predicted rates. The dashed line shows the month of June 2020 (proxy for pandemic declaration month, instead of March 2020, to account for 90-day delay in refills used to calculate treatment modification). The deintensification analysis included only patients eligible for deintensification, defined as receiving at least another medication than metformin. 
to the relatively larger decline for in-person visits among those with more comorbidities.

Despite a drop in A1c measurement rates, we did not observe an effect on T2D control, as measured by A1c levels. The reduction in measurement may not have been long enough to affect T2D control, or clinicians may have been able to adjust treatment based on home blood sugar measurements reported by patients. This would be consistent with the observed increase in intensification rates during the pandemic. While this bodes well for the use of virtual visits to address T2D management, we were not able to observe the association of virtual visits and less frequent A1c measurement with longer-term outcomes. Change in A1c measurement rates was not different according to CCI score or A1c level. We might expect that providers would want relatively more frequent A1c measurements for patients with a higher A1c level or more comorbidities to maintain good T2D control. However, those same patients were also at higher risk of COVID19 complications. Fear of the risk of COVID exposure with coming to the laboratory for a test or provider willingness to tolerate higher A1c levels in sicker patients with shorter life expectancy during the pandemic may have prevented relatively higher rates of A1c testing.

A seasonal effect on A1c levels has been reported previously and is likely related to diet and physical activity modifications during the holiday and with colder weather. We observed similar patterns for treatment modification, suggesting that clinicians are reacting to Alc levels. The increase in intensification rates during the pandemic, beyond seasonal trends, suggests higher adherence or that providers felt able to actively manage patients in a period with a high proportion of virtual visits.

Patients without A1c measurement within the previous 6 months showed different trajectories in visit and treatment modification rates: an overall decrease in visit rates and intensification, and an increase in deintensification, suggesting that this subpopulation included patients no longer receiving routine T2D care at the VHA (as deintensification is defined by the lack of refill). The algorithm we used for identifying active users can only identify inactive users after a defined period without any utilization of VA services, during which they are still counted as active users. There is no incentive to formally dis-enroll from VA care as there is no charge for being enrolled.

We observed a drop in other-cause ER visits and hospitalizations at the beginning of the pandemic, followed by a rebound increase. Previous data showed a drop in nonCOVID-related ER visits and hospitalizations during the pandemic, but studied the beginning of the pandemic only. ${ }^{26,27}$ Our results are consistent with those findings. The rebound effect was not observed for hypoglycemia- and hyperglycemia-related ER visits and hospitalizations. Patients may have gone outside VHA for medical issues requiring immediate attention related to T2D, although it is not clear why they would have done this to a greater extent during the pandemic.

\section{Strengths and Limitations}

First, we could not distinguish between deintensification due to a clinician decision vs. patient nonadherence. This is a limitation of any retrospective observational study using pharmacy fills. Yet, deintensification tells us whether the patient is taking the medication or not, as pharmacy fills are able to measure medication consumption. ${ }^{28,29}$ Second, we had no information on home blood sugar records that may have contributed to clinicians' decisions to modify antidiabetics. Third, since Medicare data were not yet available, ER visits and hospitalizations occurring outside VHA were not captured. Finally, we could not account for other factors that may have affected T2D outcomes, such as modifications in diet or physical activity related to social distancing.

Our study has several strengths. First, our sample was large and representative of all US regions. Second, we adjusted all measures to account for the number of active users of the VHA each month, avoiding biasing the results towards lower numbers due to a natural decrease in total sample. Third, our study period was long enough to compare the measures during the pandemic period to natural trends before the pandemic. Finally, we assessed several outcomes allowing the evaluation of T2D management, control, and outcomes.

\section{Conclusion}

Despite a dramatic shift to virtual visits and a decrease in A1c measurement rates during the pandemic, we did not observe an effect on T2D control or short-term T2D-related outcomes which provides some reassurance about the adequacy of virtual visits. Further studies should assess the longer-term effects of shifting to virtual visits in specific patients to help to individualize care, improve efficiency, and maintain appropriate care while reducing overuse.

Corresponding Author: Carole E. Aubert, MD, MSc; Department of General Internal Medicine, Bern University Hospital, Inselspital, University of Bern, Freiburgstrasse, 3010Bern, Switzerland (e-mail: caroleelodie.aubert@insel.ch).

Supplementary Information The online version contains supplementary material available at https://doi.org/10.1007/s11606-02107301-7.

Funding This study was funded by Department of Veterans Affairs Health Services Research and Development IIR 15-131. The funding agency had no role in the design and conduct of the study; collection, management, analysis, and interpretation of the data; preparation, review, or approval of the manuscript; and decision to submit the manuscript for publication. Dr. Aubert was supported by an Early Postdoc.Mobility grant from the Swiss National Science Foundation (grant P2LAP3_184042). 


\section{Declarations:}

Conflict of Interest: The authors declare that they do not have a conflict of interest.

\section{REFERENCES}

1. Moreland A, Herlihy C, Tynan MA, et al. Timing of State and Territorial COVID-19Stay-at-Home Orders and Changes in Population Movement United States, March 1-May 31, 2020. MMWR Morb Mortal Wkly Rep 2020;69: 1198-1203.

2. Mehrota A, Chernew M, Linetsky D, Hatch H, Cutler D. The Impact of the COVID-19 Pandemic on Outpatient Visits: A Rebound Emerges. 2020. The Commonwealth Fund.

3. Centers for Disease Control and Prevention. Managing Healthcare Operations During COVID-19. https://www.cdc.gov/coronavirus/2019ncov/hcp/facility-planning-operations.html. Accessed 9 Dec 2021.

4. Danhieux K, Buffel V, Pairon A, et al. The impact of COVID-19 on chronic care according to providers: a qualitative study among primary care practices in Belgium. BMC Fam Pract 2020;21:255.

5. Kendzerska T, Zhu DT, Gershon AS, et al. The Effects of the Health System Response to the COVID-19 Pandemic on Chronic Disease Management: A Narrative Review. Risk Manag Healthc Policy. $2021 ; 14: 575-84$

6. Irmak AY, Celikkalp Ü, Ekuklu G. Evaluation of the chronic disease management and depression levels of people over 65 years of age during the COVID-19 pandemic period. Perspect Psychiatr Care 2020;57(3): 1409-1416.

7. Wright A, Salazar A, Mirica M, Volk LA, Schiff GD. The Invisible Epidemic: Neglected Chronic Disease Management During COVID-19. J Gen Intern Med. 2020;35:2816-7.

8. Wang B, Li R, Lu Z, Huang Y. Does comorbidity increase the risk of patients with COVID-19: evidence from meta-analysis. Aging (Albany NY) 2020;12:6049-57.

9. Shahid Z, Kalayanamitra R, McClafferty B, et al. COVID-19 and Older Adults: What We Know. J Am Geriatr Soc 2020;68:926-9.

10. Kerr EA, Klamerus ML, Markovitz AA, et al. Identifying Recommendations for Stopping or Scaling Back Unnecessary Routine Services in Primary Care. JAMA Intern Med 2020;180(11):1500-1508.

11. Beard AJ, Hofer TP, Downs JR, et al. Assessing appropriateness of lipid management among patients with diabetes mellitus: moving from target to treatment. Circ Cardiovasc Qual Outcomes 2013;6:66-74.

12. Kerr EA, Lucatorto MA, Holleman R, Hogan MM, Klamerus ML, Hofer TP. Monitoring performance for blood pressure management among patients with diabetes mellitus: too much of a good thing? Arch Intern Med 2012;172:938-45

13. Charlson ME, Pompei P, Ales KL, MacKenzie CR. A new method of classifying prognostic comorbidity in longitudinal studies: development and validation. J Chronic Dis. 1987;40:373-83.

14. Sussman JB, Kerr EA, Saini SD, et al. Rates of Deintensification of Blood Pressure and Glycemic Medication Treatment Based on Levels of Control and Life Expectancy in Older Patients With Diabetes Mellitus. JAMA Intern Med 2015;175:1942-9.
15. VA/DoD Clinical Practice Guidelines. Management of Diabetes Mellitus in Primary Care. 2017. https://www.healthquality.va.gov/guidelines/CD/ diabetes/. Accessed 9 Dec 2021.

16. Akaike, H. (1973). Information theory and an extension of the maximum likelihood principle. In B. N. Petrov \& F. Caski (Eds.), Proceedings of the Second International Symposium on Information Theory (pp. 267-281). Budapest: Akademiai Kiado.

17. Mehrotra A, Chernew M, Linetsky D, Hatch H, Cutler D. The impact of the COVID-19 pandemic on outpatient visits: a rebound emerges. New York, NY: Commonwealth Fund; 2020. https://www.commonwealthfund org/publications / 2020/apr/impact-covid-19-outpatientvisitsexternalicon.

18. Koonin LM, Hoots B, Tsang CA, et al. Trends in the Use of Telehealth During the Emergence of the COVID-19 Pandemic - United States, January-March 2020. MMWR Morb Mortal Wkly Rep 2020;69:1595-9.

19. Adepoju OE, Chae M, Ayadi MF, Matuk-Villazon O, Liaw W. Early Impacts of the COVID-19 Pandemic on Telehealth Patterns in Primary Care, Mental Health, and Specialty Care Facilities in Texas. South Med J 2021;114:593-6.

20. Bestsennyy O, Gilbert G, Harris A, Rost J. Telehealth: A quarter-trilliondollar post-COVID-19 reality? 2021. https://www.mckinsey.com/industries/healthcare-systems-and-services/our-insights/telehealth-a-quarter-trillion-dollar-post-covid-19-reality. Accessed 09/11/2021.

21. Patel SY, Mehrotra A, Huskamp HA, Uscher-Pines L, Ganguli I, Barnett ML. Trends in Outpatient Care Delivery and Telemedicine During the COVID-19 Pandemic in the US. JAMA Intern Med 2021;181:388-91.

22. Bădescu SV, Tătaru C, Kobylinska L, et al. The association between Diabetes mellitus and Depression. J Med Life 2016;9:120-5.

23. Anderson RJ, Freedland KE, Clouse RE, Lustman PJ. The prevalence of comorbid depression in adults with diabetes: a meta-analysis. Diabetes care 2001;24:1069-78.

24. Holt RI, de Groot M, Golden SH. Diabetes and depression. Curr Diab Rep $2014 ; 14: 491$

25. Lam K, Lu AD, Shi Y, Covinsky KE. Assessing Telemedicine Unreadiness Among Older Adults in the United States During the COVID-19 Pandemic. JAMA Intern Med 2020;180:1389-91.

26. Nourazari S, Davis SR, Granovsky R, et al. Decreased hospital admissions through emergency departments during the COVID-19 pandemic. Am J Emerg Med 2021;42:203-10.

27. Hartnett KP, Kite-Powell A, DeVies J, et al. Impact of the COVID-19 Pandemic on Emergency Department Visits - United States, January 1, 2019-May 30, 2020. MMWR Morb Mortal Wkly Rep 2020;69:699-704.

28. Grymonpre R, Cheang M, Fraser M, Metge C, Sitar DS. Validity of a prescription claims database to estimate medication adherence in older persons. Med Care 2006;44:471-7.

29. Anghel LA, Farcas AM, Oprean RN. An overview of the common methods used to measure treatment adherence. Med Pharm Rep 2019;92:117-22.

Publisher's Note: Springer Nature remains neutral with regard to jurisdictional claims in published maps and institutional affiliations. 